\title{
Techno-Economic Analysis of
} Glycerol Valorization via Catalytic Applications of Sulphonic Acid-Functionalized Copolymer Beads

\author{
Luma Sh. Al-Saadi ${ }^{\star}$, Valentine C. Eze and Adam P. Harvey \\ School of Engineering, Newcastle University, Newcastle upon Tyne, United Kingdom
}

The design of experiments response surface analysis was employed for the first time to study the effect of divinylbenzene (DVB) (20-80 wt. \%), diluent (0-100 wt.\%), and mixing (200-900 rpm) on the beads' physical properties and on swelling ability. The beads with the highest performances, in terms of mechanical stability, surface area, and swelling ability, were sulphated, and tested in converting glycerol to a valuable product "solketal." Process options for glycerol valorization to solketal using synthesized sulphonic acid-functionalized styrene-divinylbenzene (ST-DVB-SO ${ }_{3} \mathrm{H}$ ) copolymer beads and techno-economic analysis of the processes have been investigated. Three processes were evaluated: two one-stage processes at $8.5 \mathrm{wt} . \%$ catalyst and $50^{\circ} \mathrm{C}$,

Edited by:

Mohamed Kheireddine Aroua, Sunway University, Malaysia

Reviewed by:

Ching Shya Lee,

University of Malaya, Malaysia Maciej Trejda,

Adam Mickiewicz University, Poland

*Correspondence:

Luma Sh. Al-Saadi

lumashihab201@gmail.com

Specialty section:

This article was submitted to Green and Sustainable Chemistry,

a section of the journal

Frontiers in Chemistry

Received: 30 November 2018 Accepted: 06 December 2019

Published: 10 January 2020

Citation:

Al-Saadi LS, Eze VC and Harvey AP (2020) Techno-Economic Analysis of

Glycerol Valorization via Catalytic Applications of Sulphonic Acid-Functionalized Copolymer

Beads. Front. Chem. 7:882

doi: 10.3389/fchem.2019.00882 based on either 6:1 acetone to glycerol molar ratio (87\% conversion) or 12:1 (98\% glycerol to solketal conversion), and a two-stage route (two acetone additions), where $\geq 98 \%$ conversion can be achieved with lower overall acetone use (10:1 acetone to glycerol molar ratio and $50^{\circ} \mathrm{C}$ ). Techno-economic analyses of the three solketal options were performed using Aspen (HYSYS), based on a fixed capacity of 100,000 te/y and 20-years lifetime. The techno-economic analyses showed that the net present values for the solketal process options were $\$ 707 \mathrm{M}$ for the two-stage, $\$ 384 \mathrm{M}$ for the one-stage at 6:1 acetone to glycerol molar ratio, and $\$ 703 \mathrm{M}$ for the one-stage at 12:1 acetone to glycerol molar ratio. The break-even prices for these solketal processes were $\$ 2,058 /$ ton for the one-stage at 12:1 of acetone and two-stage and $\$ 2,088 /$ ton for the one-stage at 6:1 of acetone, which is lower than the current price of solketal at $\$ 3,000 /$ ton. The two-stage process was found to be the most effective method of glycerol valorization production to solketal.

Keywords: glycerol, valorization, sulphonic acid, copolymer beads, solketal

\section{INTRODUCTION}

Rapid depletion of fossil fuel and the harmful effects of its combustion on the environment have motivated the quest to find an economic and effective method to produce renewable fuels with less harmful environmental effects. Bio-fuels, such as biodiesel, have emerged as an environmentally friendly and sustainable substitute to petro-diesel (Demirbas, 2008; Helwani et al., 2009). Biodiesel is most commonly produced via triglyceride transesterification, which produces fatty acid alkyl 
esters as the main product and crude glycerol as a by-product (Melero et al., 2009; Patil et al., 2009; Kim et al., 2011; Park et al., 2015). It is envisaged that the use of metal oxides, and hydroxide and sulphonic acid-functionalized resin catalysts for biodiesel production, will produce glycerol of high market value, increasing the commercial viability of biodiesel production. The co-production of glycerol in the conventional biodiesel processes has little economic advantage on biodiesel plants as the huge rise in global glycerol production has caused its oversupply, significantly reducing the glycerol price (Rodrigues et al., 2012). Glycerol surplus has increased from 200,000 tons in the year 2003 to over 2 million tons in 2011, and this is predicted to rise to over 6 million tons in 2025 (Ciriminna et al., 2014). Therefore, it is important to find a way to upgrade glycerol into valuable products. Indeed many alternatives have been suggested to utilize glycerol in many fields such as animal food, drugs, cosmetics, tobacco, fuel additives, waste treatment, and production of different chemicals (Knothe et al., 2010; Leoneti et al., 2012; Yang et al., 2012). It also can be used to reduce the free fatty acid content in biodiesel feedstocks, which could help to reduce many of problems related to separation duties and toxicity (Leung et al., 2010). Previous studies have shown that crude glycerol could be converted via a biological process to produce valuable chemicals such as 1,3-propanediol (Mu et al., 2006), citric acid (Papanikolaou et al., 2002), and polyhydroxyalkanoates (Ashby et al., 2004). A promising route for glycerol utilization is reaction with acetone in the presence of an acid catalyst to form 2,2dimethyl 1,3-dioxalane-4-methanol, also called "solketal" (Mota et al., 2010). The reaction of acetone and glycerol to produce solketal is shown in Figure 1. The reaction is limited by the thermodynamic equilibrium, as complete glycerol conversion cannot be achieved due to water formation (Li et al., 2012; Nandan et al., 2013; Rossa et al., 2017), and long residence time and high amount of acetone are required to overcome this problem (Khayoon and Hameed, 2013). Solketal is a valuable product used as an additive to improve the fuel properties of gasoline and biodiesel, in pharmaceutical industry, and as a plasticizer in the polymer industry (Nanda et al., 2014a).

Conventional processes for solketal production use homogeneous acid catalysts such as p-toluenesulfonic acid (Suriyaprapadilok and Kitiyanan, 2011) and sulfuric acid (Dmitriev et al., 2016), which leads to an increase in the cost of production due to the extra costs of downstream separation of the homogenous catalyst as well as damage to the equipment due to its corrosive ability; thus it cannot be reused. Some homogenous acid catalysts can be easily recovered such as $\mathrm{SnF}_{2}$-catalyst (da Silva et al., 2017) and $\mathrm{SnCl}_{2}$-catalyst (Menezes et al., 2013), although the presence of chlorides from $\mathrm{SnCl}_{2}$ in the reactor can cause corrosion in reactors and pipes. To overcome this problem, heterogeneous catalysts can be used as it is more environmentally friendly than homogenous catalysts; thus, it can be recycled and reused many times, which turn the production process to "green." Glycerol acetalization was researched using heterogeneous acid catalysis such as $\mathrm{Ni}-\mathrm{Zr}$ supported on mesoporous activated carbon (Khayoon and Hameed, 2013), zeolite H-BEA (SAR 19) (Rossa et al., 2017), Zr- and Hf-TUD-1 and Sn-MCM-41 (Li et al., 2012), and sulfonic mesostructured silica (Vicente et al., 2010). However, these catalysts have lower rates of reaction than homogeneous catalysts. An alternative is to use an ion-exchange resin supported catalyst, produced from co-polymerization of styrene and divinylbenzene (DVB). Due to the presence of DVB in the structure, the polymeric resin beads swell during the reaction, providing easy access of reactants to the catalytic active sites (Sharma et al., 2011; Boz et al., 2015), such that high reaction rates can be achieved. Ion-exchange resins can be regenerated (Tesser et al., 2010) and reused many times (Huang et al., 2012). Above all, Amberlyst resins, such as Amberlyst 35, exhibit excellent performance in glycerol acetalization (Nanda et al., 2014b). Resin catalysts have been synthesized with variety of physical properties, as the cross linking level has been varied from low for Dowex HCR-W2 and Amberlyst-16 to high for Amberlyst-15 and Amberlyst35 (Özbay et al., 2008). Different structures (macro-porous and gel-type) were used in the transesterification reaction of biodiesel production; different surface areas, pore diameters, and porosities were produced (Fu and Borges, 2015). The results showed that the physical properties of catalyst such as pores and surface area have more effect on catalytic performance than that of cross-linking level. The catalyst types in order of decreasing activity are A-15 > A-35 >A-16 > Dowex HRC-W2 (Özbay et al., 2008). The authors revealed that the difference between using the abovementioned catalysts as a particle or as a powder is only $10 \%$ (Özbay et al., 2008). More study is required to investigate the feasibility of the use of other types of resin structures, such as non-porous and large porous structures.

In the resin synthesis, the organic phase (discrete phase) consists of monomer (i.e., styrene), cross linker (DVB), initiator (benzoyl peroxide), and a porogen, which can be either a solvent, such as toluene, or a non-solvent, such as heptane. The aqueous phase consists of emulsion stabilizer such as hydroxyethyl cellulose, gelatine, and sodium chloride (Gokmen and Du Prez, 2012; Yussof, 2012). The volume of the aqueous to the organic phase is usually fixed above 3:1 (Coutinho et al., 1998).

When toluene was used as a solvent in discrete phase, adding of monomer droplet leads to building a crosslinking continuously. When the crosslinking becomes rigid, it enables to absorb toluene at "a gelation point." After that the de-swelling (separation) phase occurs. The predominant beads in this case are micro or meso-pores with high surface area and low pore volume (Gokmen and Du Prez, 2012).

Conversely, a non-solvent porogen (such as n-heptane) cannot dissolve or swell the polymer chain, so the separation phase occurs before gelation point. In this case, large pore volumes and very low surface areas of macroporous particles were obtained (Gokmen and Du Prez, 2012) (see the chemical structure of ST-DVB in Figure 2).

However, the styrene-divinylbenzene (ST-DVB) copolymerization must be optimized for the production of copolymers of desirable particle sizes, surface area, and physical properties.

In this study, process options for glycerol valorization to solketal using sulphonic acid-functionalized (ST-DVB-SO ${ }_{3} \mathrm{H}$ ) copolymer beads and techno-economic analysis of the processes were investigated. The solketal processes evaluated were one- 
<smiles>OCC(O)CO</smiles>

Glycerol

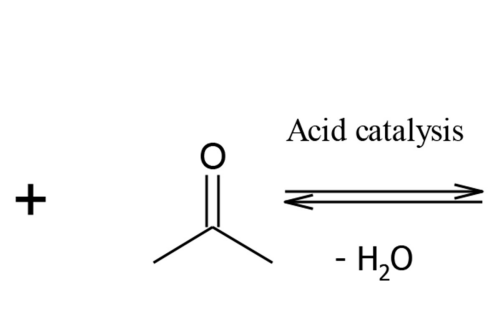

Acetone

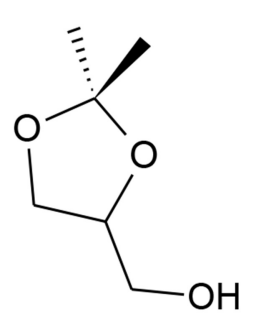

2,2-dimethyl-[1,3] dioxane-4-yl)-methanol (five-membered solketal,5)<smiles>CC1(C)OCC(O)CO1</smiles>

2,2-dimethyldioxane-5-ol(sixmembered acetal,6)

FIGURE 1 | Producing solketal from glycerol (Khayoon and Hameed, 2013).<smiles>C=Cc1ccccc1</smiles>

Styrene<smiles>C=Cc1ccc(C=C)cc1</smiles>

divinylbenzene

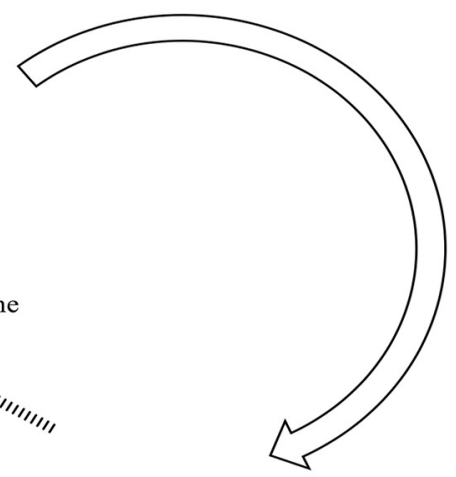

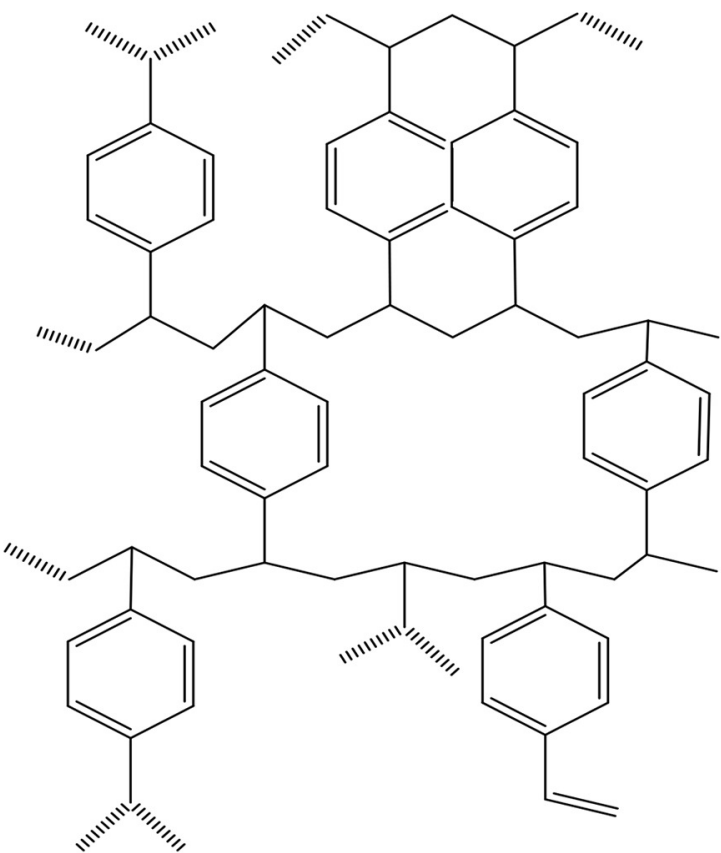

FIGURE 2 | Chemical structure of ST-DVB resin.

and two-stage acetalization processes using synthesized and sulphonic acid-functionalized ST-DVB copolymer beads of desirable properties. The glycerol acetalization process was optimized to overcome the equilibrium limitation and ensure high solketal yields. The ST-DVB copolymer beads were chosen as the sulphonic acid support because the polymerization process 
could be tailored to achieve copolymer beads of different physical properties. Techno-economic analysis based on Aspen (HYSYS) was applied to evaluate the different process options for glycerol valorization to solketal.

\section{MATERIALS AND METHODS}

\section{Materials}

The chemicals used in the experiments were styrene (>99\%), divinylbenzene (80\%), benzoyl peroxide (75\%), gelatine from bovine skin (99.5\%), heptane (99.9\%), toluene (99.9\%), 2-hydroxyl ethyl cellulose, vinyl benzene chloride (97\%), poly(vinyl alcohol) (>99\% hydrolysed), 2,2'-Azobis(2methylpropionitrile) of $0.2 \mathrm{M}$ in toluene, and sodium chloride (>99\%). These chemicals were purchased from Sigma-Aldrich, UK. Amberlyst ${ }^{\mathrm{TM}}$ 70, supplied by Dow Chemical Company, Netherlands, was used for catalytic activities comparison, with the synthesized ST-DVB-SO ${ }_{3} \mathrm{H}$ copolymer beads.

\section{Synthesis and Characterization of Sulphonic Acid-Functionalized ST-DVB Copolymer Beads}

The ST-DVB copolymer beads were produced by suspension polymerization of the styrene and divinylbenzene monomers. Copolymerization was carried out in a 500-ml three-necked batch reactor equipped with a heater-stirrer (IKA RCT basic), a reflux condenser, and a nitrogen inlet pipe (Figure 3) was used to carry out the copolymer synthesis. The heater-stirrer was used to control the reaction temperature and the mixing speed.

The copolymerization mixture contained organic phase with monomer compositions of 36 wt.\% styrene and 64 wt.\% divinylbenzene and the $84 \mathrm{wt} . \%$ diluent based on the total monomers solution. The diluent used was a solution of 40:60 toluene-to-heptane volume ratio. The aqueous phase in the suspension polymerization contained de-ionized water with 0.2 wt.\% hydroxyl ethyl cellulose, 0.5 wt.\% gelatine, and 0.5 wt.\% sodium chloride. About 1 wt.\% of benzoyl peroxide was added to monomers as an initiator before starting each batch of polymerization.

Copolymerization was conducted using 3:1 aqueous-toorganic phase volume ratio, $90^{\circ} \mathrm{C}$ temperature, mixing intensity of $900 \mathrm{rpm}$, and reaction time of $24 \mathrm{~h}$. Preliminary investigations, using design of experiment methodology, showed that these experimental conditions are optimal in achieving the desired STDVB copolymer particle sizes and properties. The copolymer beads were washed three times with de-ionized water (until the water became clear) and with ethanol to remove the aqueous phase or any unreacted monomers (Coutinho et al., 1998; Kangwansupamonkon et al., 2002). The ST-DVB beads were also washed with methanol, dried under $60^{\circ} \mathrm{C}$ for $48 \mathrm{~h}$ (Yussof, 2012), and stored for characterization and sulphonic acid functionalization. Design of experiments, using a response surface method, with stepwise analysis was used to investigate the copolymerization conditions.

The styrene-DVB copolymer beads in each polymerization batch were characterized in terms of their morphology, particle size distributions, bead density, surface area, and swelling ratio. Morphology of the resin beads was measured by mounting the samples on aluminum stubs, followed by analysis of their microstructure in low-vacuum mode at $2 \mathrm{kV}$, using an environmental scanning electron microscope (Hitachi S2400) equipped with a field emission gun (FEI X30 ESEM-FEG). Sieves with mesh sizes from $2 \mathrm{~mm}$ at the upper and $1 \mathrm{~mm}, 425,335,212$, and $75 \mu \mathrm{m}$ at the lower were used. The amount of copolymer beads retained in each sieve and the percentage weights used to calculate the average particle size diameter were obtained. The apparent density of the copolymer beads was determined using Equations 1-3 by gravity method based on the physical properties of the polymers as reported elsewhere (Kangwansupamonkon et al., 2002). The experimental swelling ratio of polymer $(S)$ was obtained using Equation 4 by immersing the polymer in excess toluene for $24 \mathrm{~h}$ in a tube covered and sealed with aluminum foil (Kangwansupamonkon et al., 2002). The surface area of the beads was calculated based on particle radius and apparent density using Equation 5.

$$
\text { Regular particles }=\frac{\text { mass of the polymer }}{\text { volume of occupied container }}
$$

Small particles or powder $=\frac{\text { mass of the polymer }}{\text { volume of the polymer from mark of cylinder }}$

$$
\begin{aligned}
\text { Irregular particles } & =\frac{\text { mass of the polymer }}{\text { volume of displaced water }} \\
\mathrm{S} & =1+\left(\frac{\mathrm{W}_{\mathrm{S}}}{\mathrm{W}_{\mathrm{p}}}-1\right) \frac{\rho_{\mathrm{p}}}{\rho_{\mathrm{S}}}
\end{aligned}
$$

$$
\begin{aligned}
\text { surface area } & =\frac{\text { area of the particles }\left(4 \pi \mathrm{R}^{2}\right)}{\text { volume of the particles }\left(\left(\frac{4}{3}\right) * \pi \mathrm{R}^{3}\right)} *\left(\frac{1}{\rho_{\mathrm{p}}}\right) \\
& =\frac{3}{\mathrm{R}^{*} \rho_{\mathrm{p}}}
\end{aligned}
$$

where $W_{\mathrm{s}}$ and $W_{\mathrm{p}}$ are the weights of the fully swollen polymer and the dry polymer, respectively. $\rho_{p}$ and $\rho_{s}$ are the densities of polymer and solvent, respectively, while $R$ represents the average radius of polymer particles.

The dried ST-DVB copolymer beads were functionalized with sulphonic acid sites by treatment with hot, concentrated sulphuric acid. About $5 \mathrm{~g}$ of the copolymer beads were transferred into $200 \mathrm{ml}$ concentrated sulphuric acid at $90^{\circ} \mathrm{C}$ and sulphonated for $160 \mathrm{~min}$. On completion of the sulphonation, the reaction mixture was poured over ice to quench the reaction, and the sulphonated copolymer beads were washed up to four times with de-ionized water, acetone, and methanol and dried at $60^{\circ} \mathrm{C}$ for $48 \mathrm{~h}$. The ST-DVB-SO ${ }_{3} \mathrm{H}$ copolymer beads were characterized, and the active sites content was quantified through sulfur content analysis using Elementar Vario Max CNS Analyser. The synthesized ST-DVB-SO ${ }_{3} \mathrm{H}$ copolymer beads were applied as heterogeneous catalysts for glycerol acetalization to solketal. In the catalytic applications, the spent ST-DVB-SO ${ }_{3} \mathrm{H}$ copolymer beads were regenerated by treatment with $0.1 \mathrm{M} \mathrm{HCl}$, washing three times with water, and drying at $120^{\circ} \mathrm{C}$. 


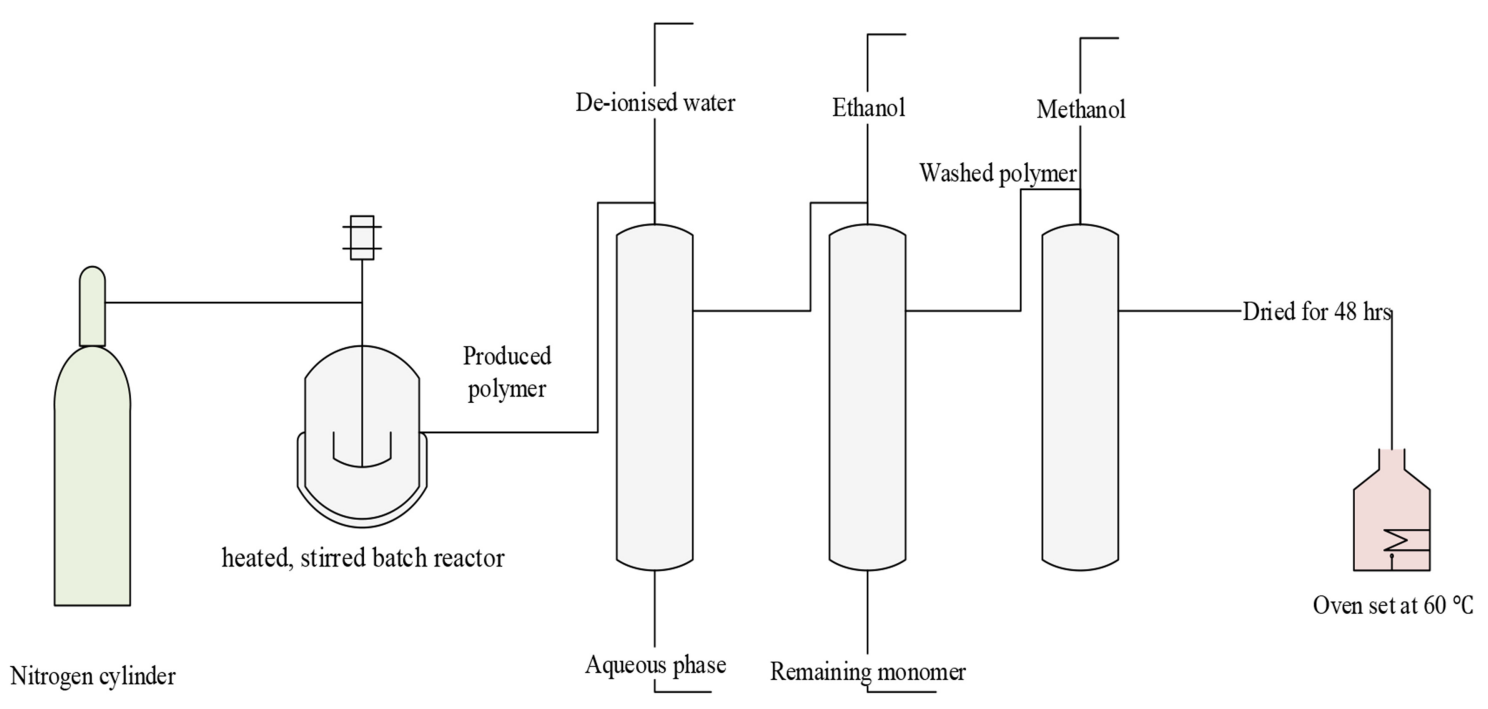

FIGURE 3 | Schematic diagram of copolymerization of styrene and DVB.

\section{Glycerol Valorization to Solketal Using the ST-DVB- $\mathrm{SO}_{3} \mathrm{H}$ Catalyst}

Heterogeneously catalyzed glycerol acetalization to solketal by catalytic applications of the synthesized ST-DVB- $\mathrm{SO}_{3} \mathrm{H}$ copolymer beads was investigated using a statistical design of experiments, response surface methodology with stepwise analysis. The reaction conditions investigated were acetone to glycerol molar ratios of 2:1-6:1, 1-20 min residence time, reaction temperatures of $30-50^{\circ} \mathrm{C}$, fixed catalyst of $8.5 \mathrm{wt} . \%$ (based on the glycerol feed), and $800 \mathrm{rpm}$ mixing intensity to ensure that the reactions were kinetically controlled. The glycerol acetalization experiments were performed in a 250-ml batch reactor equipped with a heater-stirrer and reflux condenser. In each experiment, $92.09 \mathrm{~g}$ of glycerol and $232.32 \mathrm{~g}$ of acetone (for 4:1 acetone to glycerol molar ratio) were charged into the reactor and heated to the reaction temperature. This was followed by adding $7.83 \mathrm{~g}$ of the ST-DVB- $\mathrm{SO}_{3} \mathrm{H}$ copolymer catalyst and mixing at $800 \mathrm{rpm}$.

More experiments were carried out based on the observations from the abovementioned experimental design to investigate other process options for solketal production using one- and two-stage processes at 6:1-12:1 acetone to glycerol molar ratios and $30 \mathrm{~min}$ offixed reaction time. Two cases of one-stage glycerol acetalization process were investigated at $6: 1$ and 12:1 acetone to glycerol molar ratios, using 8.5 wt.\% of ST-DVB$\mathrm{SO}_{3} \mathrm{H}$ copolymer catalyst and at $50^{\circ} \mathrm{C}$. The two-stage process was performed using a first-step glycerol acetalization at 10:1 of acetone to glycerol molar ratio, 8.5 wt.\% ST-DVB-SO ${ }_{3} \mathrm{H}$ copolymer catalyst, and $50^{\circ} \mathrm{C}$, followed by flash distillation at 10 mbar and $40^{\circ} \mathrm{C}$, and a second glycerol acetalization step using fresh acetone. About $1 \mathrm{ml}$ of sample was collected at various time intervals during the reactions using a micropipette, and these were filtered through a $150-\mu \mathrm{m}$ stainless steel wire mesh in 2-ml vials. All the samples collected were analyzed immediately using gas chromatography.

\section{Sample Analysis Using Gas Chromatography}

The collected samples were analyzed using a 6890 Hewlett Packard gas chromatograph (GC). About $50-80 \mathrm{mg}$ of the homogenized sample was measured into a 2-m GC vial, followed by the addition of $1 \mathrm{ml}$ of $10 \mathrm{mg} \mathrm{mL}^{-1}$ of methyl heptadecanoate prepared in 2-propanol. The prepared samples were analyzed using GC by injection of $1 \mu \mathrm{l}$ of sample with a 5- $\mu \mathrm{l}$ SGE GC syringe. The GC was equipped with a fused silica capillary column of $30 \mathrm{~m}$ length, $0.32 \mathrm{~mm}$ internal diameter, and film thickness of $0.25 \mu \mathrm{m}$. The GC oven temperature program was $120^{\circ} \mathrm{C}$ for $5 \mathrm{~min}$ initially and ramping up from 120 to $260^{\circ} \mathrm{C}$ at a heating rate of $15^{\circ} \mathrm{C} / \mathrm{min}$, which was held for another $15 \mathrm{~min}$. The injector and flame ionization detector temperatures were set at $250^{\circ} \mathrm{C}$ and $260^{\circ} \mathrm{C}$, respectively. The glycerol and solketal contents were quantified using a calibration data which were obtained from the response factors of the solutions of glycerol/solketal and methyl heptadecanoate standard prepared in 2-propanol. Glycerol and solketal conversions were calculated using Equations 6, 7, respectively.

Glycerol conversion $(\%)=\frac{\text { Glycerol content of the sample }}{\text { Initial glycerol content }} * 100$

$$
\text { Solketal yield }(\%)=\frac{\text { Solketal content of the sample }}{\text { Maximum theoretical solketal }} * 100
$$

\section{Techno-Economic Analysis of the Glycerol Acetalization Process Options}

Aspen (HYSYS) was used to simulate the three process options that have been investigated to produce solketal from the heterogeneously catalyzed acetalization of glycerol in the presence of the synthesized ST-DVB-SO ${ }_{3} \mathrm{H}$ copolymer catalyst. 
In this study, the process plants were simulated at fixed capacity of 100,000 tons/year, 20 years lifetime, and fixed residence time of $30 \mathrm{~min}$. The flowsheet in Figure 4 was proposed for all three solketal process plants. The one-stage solketal process plants operated at 8.5 wt.\% ST-DVB-SO ${ }_{3} \mathrm{H}$ copolymer catalyst and $50^{\circ} \mathrm{C}$, based on either $6: 1$ with $87 \%$ glycerol to solketal yield (based on the experimental data; Figure 4A) or 12:1 of acetone to glycerol molar ratio with $98 \%$ glycerol to solketal yield (based on the experimental data; shown in Figure 4B). Figure 4C shows the third solketal process, which was based on glycerol acetalization at 10:1 of acetone to glycerol molar ratio, $8.5 \mathrm{wt} . \%$ ST-DVB-SO3H copolymer catalyst, and $50^{\circ} \mathrm{C}$ with $84 \%$ glycerol to solketal yield in the first step (based on the experimental data), followed by removal of reactively formed water, and another glycerol acetalization step at the same reaction conditions to achieve a total of $98 \%$ glycerol to solketal yield (based on the experimental data). The NRTL model was chosen to model this process (Sakdasri et al., 2018). The economic viability of these glycerol acetalization processes were evaluated based on the 20years net present values (NPV) and the sensitivities of the plants' profit margins to the fluctuations in the reactant and product market prices.

The sensitivity analyses were determined by varying the price of the reactants and the products from -50 to $+50 \%$ and calculating the effect of price changing on the net present value. The NPV is the cumulative discounted free cash at the end of the project (in this study, it was based on 20 years of operation and 1 year of construction); it was calculated using Equation 8. The trends in reactant and product prices lead to changes in the break-even price of the produced biodiesel, which is measured as the minimum selling price of biodiesel to achieve positive NPV.

$$
N P V=\sum_{t=1}^{T} \frac{C_{i n, t}}{(1+r)^{t}}-C_{\text {out }}
$$

where $C_{\mathrm{in}}, t$ represents net cash inflow in time $t, C_{\text {out }}$ represents initial capital expenditure, and $r$ is the discount rate.

The economic analysis of the various biodiesel processes in this study was based on the following assumptions:

I RSO feed of 100,000 tons/years was chosen as a case study

II Plant lifetime of 20 years

III Pump efficiency of $75 \%$

IV Equipment purchase costs from the HYSYS database

$\mathrm{V}$ The total investment cost was calculated based on the investment cost required to build the plant in addition to operating cost.

\section{RESULTS AND DISCUSSION}

\section{Synthesis, Functionalization, and Characterization of the Copolymer Beads}

Table 1 shows the properties of the copolymer beads produced at various process conditions. The data were analyzed using the stepwise response surface method, implemented in Minitab 17. This analysis was applied to evaluate the effects of the operating parameters and generate empirical models for the average particle size, surface area, and swelling ratio. The experiments carried out at $200 \mathrm{rpm}$ were ignored as no particles were formed at that mixing condition. All of the experiments were repeated twice.

The average particle size, the swelling ratio, and the surface area for the styrene-DVB copolymer beads are predicted by the empirical models in Equations 9-11, respectively.

Particle size $(\mathrm{mm})=1.9734-0.05624 \mathrm{X}-0.00547 \mathrm{Y}-0.000523$ $\mathrm{Z}+0.000718 \mathrm{X}^{2}-0.000102 \mathrm{X}^{*} \mathrm{Y}+0.000011 \mathrm{Y}^{*} \mathrm{Z}$.

$$
R^{2}=96.3 \%
$$

Swelling ratio $=3,150-18.89 \mathrm{X}-56.71 \mathrm{Y}-6.221 \mathrm{Z}-0.1711 \mathrm{X}^{2}$ $+0.05423 \mathrm{Y}^{2}+0.000576 \mathrm{Z}^{2}-1.456 \mathrm{X}^{*} \mathrm{Y}+0.08621 \mathrm{X}^{*} \mathrm{Z}+$ $0.1396 \mathrm{Y}^{*} \mathrm{Z}$.

$$
R^{2}=95.3 \%
$$

Surface area* $10^{-5}\left(\mathrm{~m}^{2} / \mathrm{gm}\right)=-1.961+0.1625 \mathrm{X}+0.01182$ $\mathrm{Y}+0.000213^{*} \mathrm{Z}-0.001611 \mathrm{X}^{2}-0.000096 \mathrm{Y}^{2}-0.000149 \mathrm{X}^{*} \mathrm{Y}+$ $0.000006 \mathrm{Y}^{*} \mathrm{Z}$

$$
R^{2}=99 \%
$$

where $X$ is the weight percent of DVB, $Y$ is the weight percent of the diluent, and $Z$ is the mixing speed in revolution per minute.

Contour plots of the experimental data in Figure 5 and data in Table 1 show that mixing has a clear effect on particle size. This is because mixing is required to overcome the reactants' viscosities to generate small monomer beads. There was no substantial change in average particle size when increasing the value of diluent from 0 to $50 \%$ as the average particle sizes that obtained from empirical equation were ranged $(0.42-0.62 \mathrm{~mm})$ (see Figure 5A), which is consistent with what has been reported elsewhere (Kangwansupamonkon et al., 2002).

Whereas increasing the diluent above 50 wt.\% can lead to synthesis of styrene-DVB particles of smaller sizes due to substantial reduction in solution viscosity [see entries $(3,4)$ and $(6,7)$ in Table 1 and Figure 6]. To obtain small particle size $(\leq 0.3 \mathrm{~mm})$ at high diluent $(80-100 \%)$, little mixing is required as shown in Figure 5A as increasing the diluent leads to reduced concentrations. For example, at diluent (80-100\%), a particle size of $\leq 0.27 \mathrm{~mm}$ can be obtained at only $550-650 \mathrm{rpm}$ of mixing intensity.

Increasing the DVB contents led to increased solution viscosity and consequent formation of beads of large average size [as can be observed in entries $(4,9)$ in Table 1 ], such that high diluent amount and high mixing intensity are required to overcome solution density to get small particle size (high surface area). However, because the effect of DVB on the particle size was more than that of mixing and diluent on the bead size, the interaction between the mixing, diluent, and DVB is not significant as shown in Figures 5B,C.

It was observed that at DVB concentrations of $20-30 \%$, the particle size ranged from 0.52 to $0.7 \mathrm{~mm}$ at $0-100$ wt.\% of diluent and 550-900 rpm of mixing intensity as shown in 


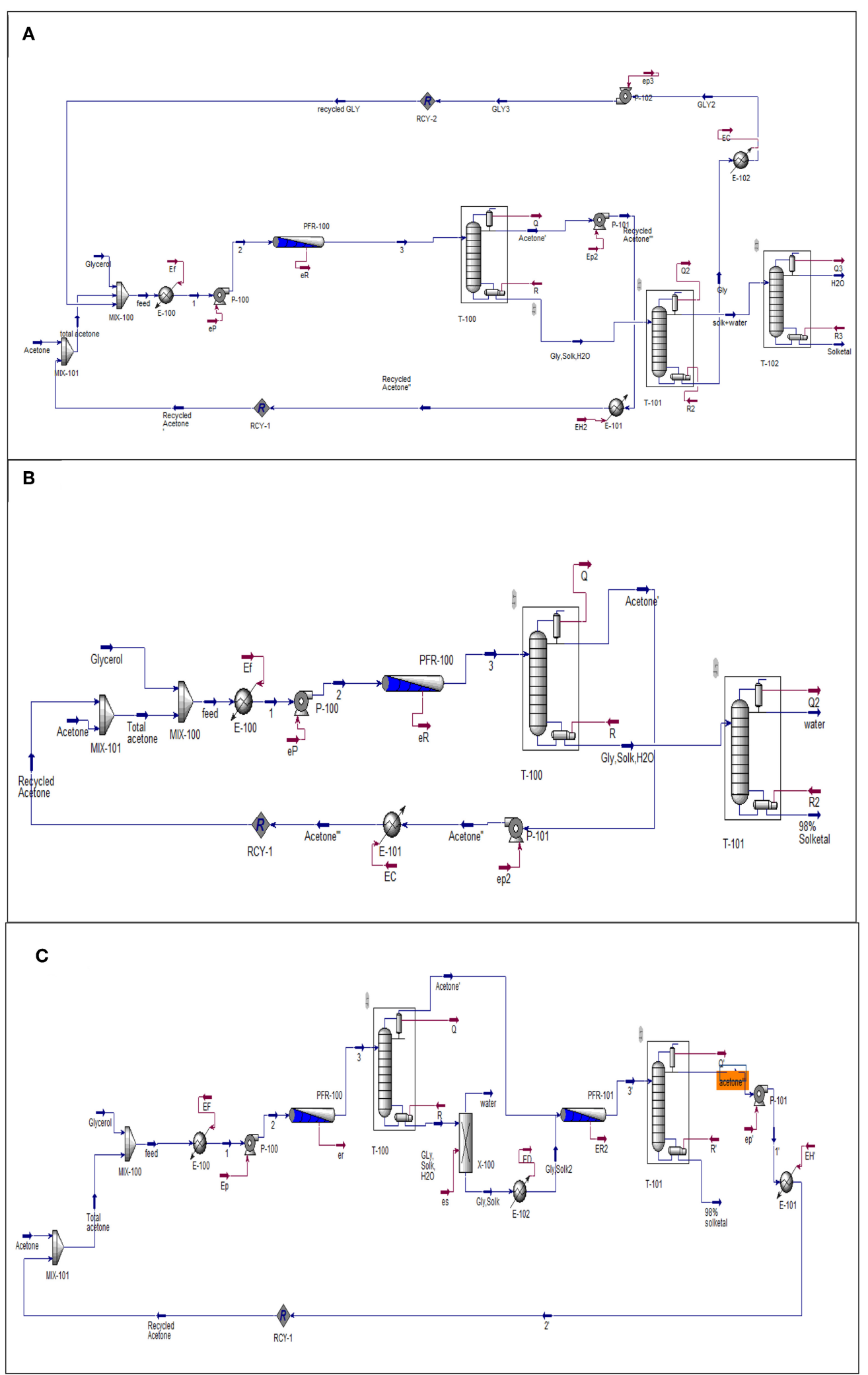

FIGURE 4 | Flowsheet diagram of glycerol acetalization reaction. (A) One-stage process (low acetone), (B) one-stage process (high acetone), and (C) two-stage process. Gly is glycerol, Solk is solketal, Mix is mixture, $\mathrm{E}$ is heat exchanger; T-100, T-101, and T-102 are distillation columns, PFR is a plug flow reactor. P-100, P-101, and P-102 and pumps and all the streams in red lines represent the energy required by the equipment. 
TABLE 1 | Characteristics of ST-DVB copolymer beads produced at different reaction conditions.

\begin{tabular}{|c|c|c|c|c|c|c|c|}
\hline Run number & $\begin{array}{l}\text { DVB } \\
\text { wt. } \%\end{array}$ & $\begin{array}{l}\text { Diluent } \\
\text { (wt.\%) }\end{array}$ & Mixing (rpm) & $\begin{array}{l}\text { Average particle } \\
\text { diameter }(\mathrm{mm})\end{array}$ & Swelling ratio & $\begin{array}{l}\text { Surface area } \\
\qquad\left(\mathrm{m}^{2} / \mathrm{gm}\right)\end{array}$ & Particle shape \\
\hline 1 & 20 & 50 & 900 & 0.753 & 491.0 & 132 & Spherical \\
\hline 2 & 20 & 50 & 200 & - & 133.0 & - & No particles \\
\hline 3 & 20 & 0 & 550 & 0.856 & 337.7 & 76 & Spherical \\
\hline 4 & 20 & 100 & 550 & 0.69 & 264.5 & 103 & Spherical \\
\hline 5 & 50 & 50 & 550 & 0.416 & 174.0 & 240 & Spherical \\
\hline 6 & 50 & 0 & 900 & 0.493 & 288.0 & 233 & Spherical \\
\hline 7 & 50 & 100 & 900 & 0.393 & 455.0 & 237 & Spherical \\
\hline 8 & 80 & 50 & 200 & - & 391.0 & - & No particles \\
\hline 9 & 80 & 100 & 550 & 1 & 593.0 & 22 & Spherical \\
\hline 10 & 80 & 0 & 550 & 1.78 & 1082 & 42 & Spherical \\
\hline
\end{tabular}
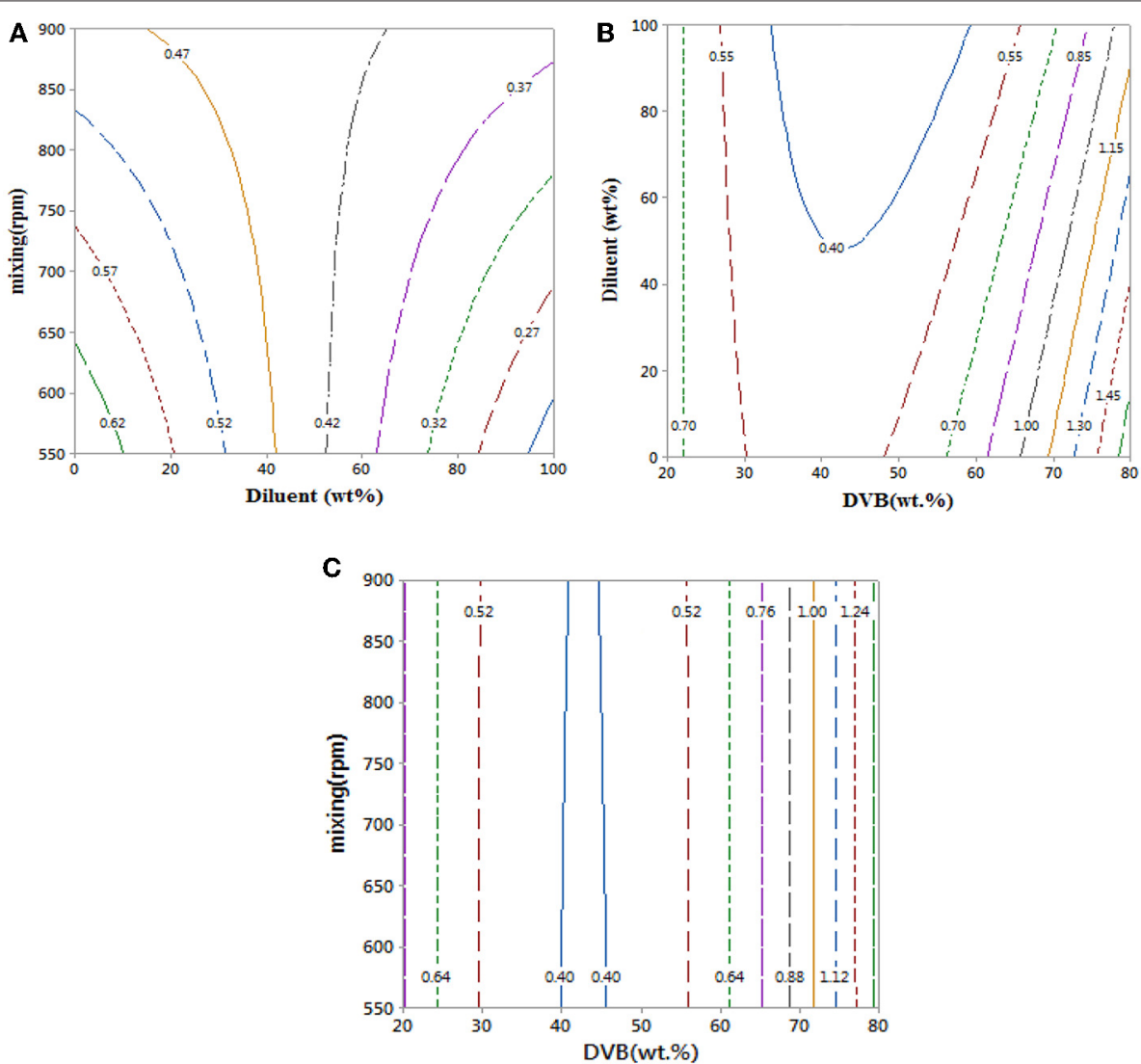

FIGURE 5 | (A-C) Contour plots showing the effect of reaction parameters on bead particle sizes. At hold values of DVB 50 wt. $\%$, 50 wt. $\%$ of diluent: monomer (wt.\%), and 725 rpm.

Figures 5B,C. However, under the same operating conditions at $40-50 \%$ of DVB, the particle sizes reduced to $0.4 \mathrm{~mm}$; this is because at very small amounts of DVB (20-30 wt.\%), the crosslinking between the particles is weak; therefore, the particles agglomerated to form larger particles than at higher DVBs (40-50 wt.\%). They increased again to $\geq 0.85 \mathrm{~mm}$ at high crosslinking beads of DVB (60-80 wt.\%) due to the increasing of solution viscosity.
It has been reported that high DVB and diluent contents led to the formation of highly cross-linked styrene-DVB particles, whereas the level of crosslinking was lower in the copolymer particles produced at lower DVB contents (Kangwansupamonkon et al., 2002).

In summary, increasing the DVB content leads to higher degrees of crosslinking in the styrene-DVB particles and higher viscosity of the polymerization solutions. Therefore, to control 

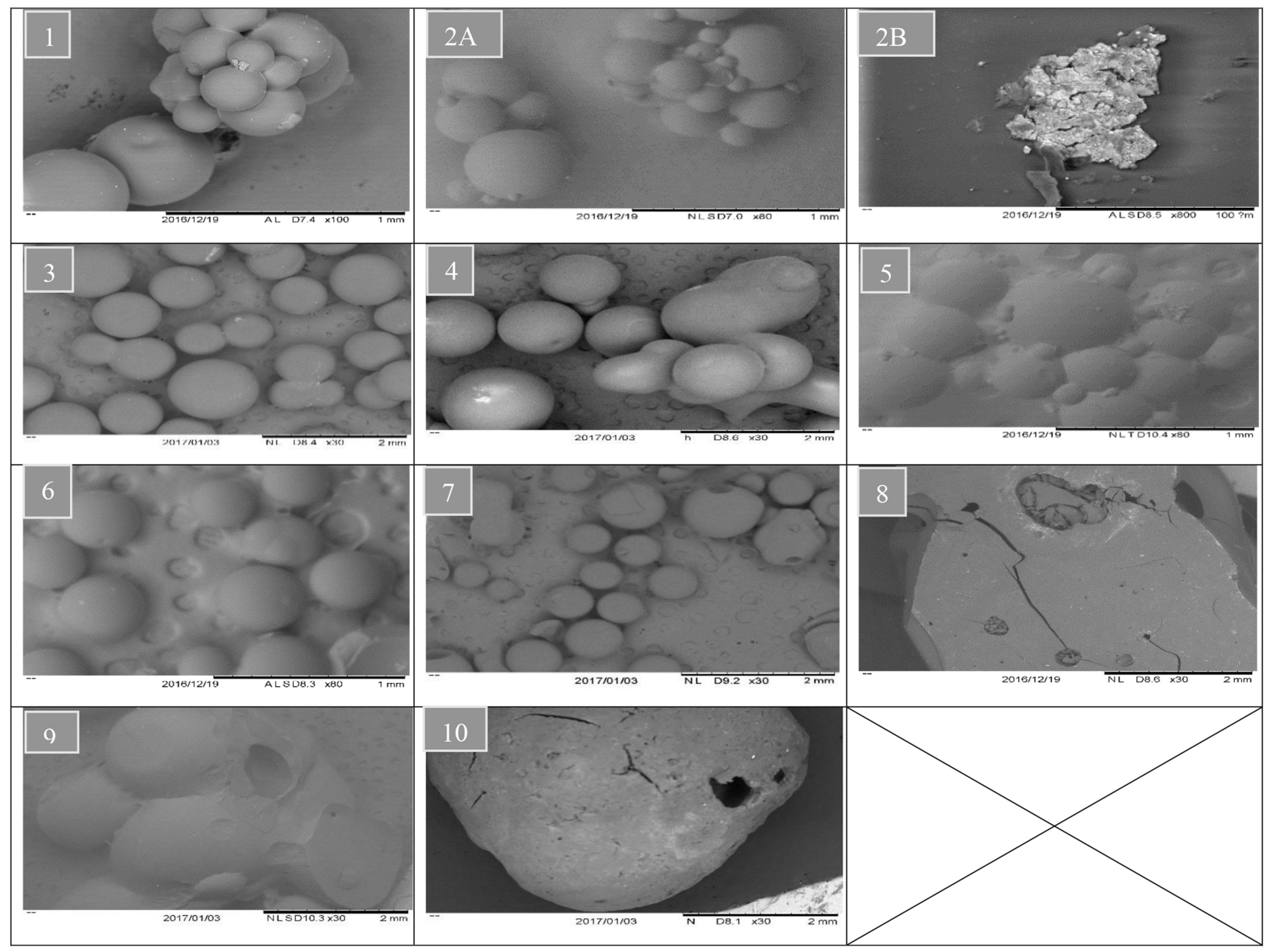

FIGURE 6 | SEM analysis of different samples. The sample number indicating runs number in Table 1.

the particle sizes and to synthesis styrene-DVB copolymer beads with substantial degrees of crosslinking, the mixing speed, DVB, and diluent contents must be controlled. For instance, high mixing and diluent content were required to produce small particle sizes in the range of $0.3-0.6 \mathrm{~mm}$, while low diluent contents and mild mixing produced large particle sizes $>1 \mathrm{~mm}$.

Depending on the particle size, the surface area of the bead varied. As can be seen in Table 1, the surface area of the beads is inversely proportional to the particle diameters, as when the particle diameter decreased from $0.75 \mathrm{~mm}$ (run 1) to $0.39 \mathrm{~mm}$ (run 7) for example, the surface area increased from 132 to 237 $\mathrm{m}^{2} / \mathrm{gm}$, respectively; so to obtain high surface area particles, small bead diameters are required.

An empirical model for the styrene-DVB beads swelling ratio in Equation 10 was used to obtain the contour plots in Figure 7, which shows the effects of the copolymer bead synthesis conditions on their swelling ratio. Swelling ratio in the copolymer beads take place via solvation of the network chain and filling of pores (Kangwansupamonkon et al., 2002).

The swelling ratio of the copolymer particles increased with mixing intensity. This is attributed to the formation of styrene-DVB beads of small particle sizes at high mixing intensity, which translates to higher particle surface area exposed to toluene and consequently higher swelling ratio as shown in Figures 7A,C. At low DVB content (20 wt.\%), increasing the amount of diluent reduces the solution viscosity, such that porous copolymer beads of small size could be achieved, even at mild mixing conditions, and consequently higher values of swelling ratio were achieved as shown in Figure 7B. When DVB contents of more than $50 \%$ were used, the copolymer beads produced were highly cross-linked, leading to low porosity (Kangwansupamonkon et al., 2002), which explains the lower swelling ratio of the styrene-DVB copolymers at $>50 \%$ content of DVB in Figures 7B,C.

At high DVB content ( $80 \mathrm{wt} . \%)$, the particles are non-porous (Kangwansupamonkon et al., 2002), so the swelling ratio is small, but when no diluent was used the particles tended to be fragile due to their high porosity as shown in Figure $6(3,6,10)$, which increased the swelling ratio (Figure 7B). At zero diluent, the polymer had a high porosity (Durie et al., 2002), so the swelling ratio was high even at high crosslinking (Figure 7C). This decreased with increasing diluent ratio $>30$ wt.\% and 

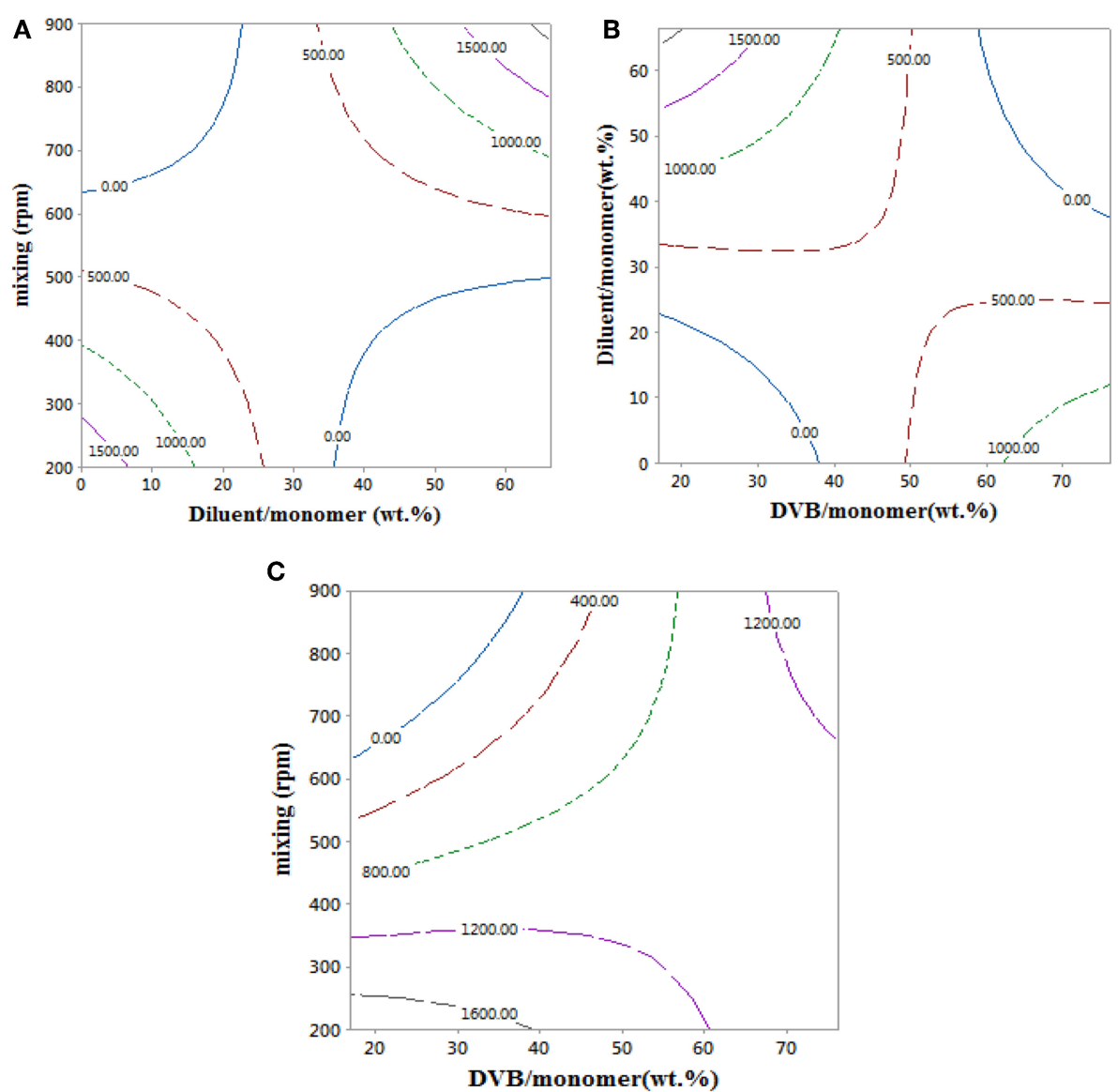

FIGURE 7 | Contour plots showing the effect of reaction parameters on swelling ratio at 0 wt. \% of diluent/monomer, 17 wt. $\%$ of DVB/monomer, and 900 rpm.

increased again at high mixing speed due to the formation of copolymer beads of small particle sizes as shown in Figure 7A. At high mixing agitation, small particle sizes are formed, such that small swelling ratio can be achieved and increased again at diluent (>30 wt.\%) and low cross-linking particle (DVB $<60$ wt.\%) as shown in Figures 7A,C.

The properties of the copolymer beads produced for the copolymerization using monomer compositions of 36 wt.\% styrene and 64 wt.\% divinylbenzene, 84 wt.\% diluent based on the total monomers' solution, $90^{\circ} \mathrm{C}$ temperature, $900 \mathrm{rpm}$ mixing intensity, and $24 \mathrm{~h}$ reaction time. The mean particle diameter for the ST-DVB-SO ${ }_{3} \mathrm{H}$ beads using sieves was $340 \mu \mathrm{m}$. Elemental analysis of the ST-DVB- $\mathrm{SO}_{3} \mathrm{H}$ copolymer beads showed that it contained $8.63 \mathrm{wt} . \%$ of sulfur, corresponding to $2.64 \mathrm{mmol}$ $-\mathrm{SO}_{3} \mathrm{H}$ per gram.

\section{Catalytic Activity and Solketal Productions Using the ST-DVB-SO ${ }_{3} \mathrm{H}$ Catalyst}

The ST-DVB- $\mathrm{SO}_{3} \mathrm{H}$ copolymer beads were characterized for their physical and chemical properties. The ST-DVB-SO ${ }_{3} \mathrm{H}$ beads were spherical with $340 \mu \mathrm{m}$ mean particle diameter. Elemental analysis of the ST-DVB-SO ${ }_{3} \mathrm{H}$ copolymer beads showed that it contained $8.63 \mathrm{wt} \%$ of sulfur, corresponding to $2.64 \mathrm{mmol}$ $-\mathrm{SO}_{3} \mathrm{H}$ per gram of copolymer beads. The active site density of the synthesized ST-DVB-SO ${ }_{3} \mathrm{H}$ copolymer catalyst beads was similar to that measured for the Amberlyst ${ }^{\mathrm{TM}} 70$, which has an acidic capacity of $2.59 \mathrm{mmol} \mathrm{H} \mathrm{H}^{+} / \mathrm{g}$ as measured by sulfur content elemental analysis (Eze and Harvey, 2018). It was also observed that the ST-DVB- $\mathrm{SO}_{3} \mathrm{H}$ had similar catalytic activity as the Amberlyst ${ }^{\mathrm{TM}} 70$ (as shown in Figure 8).

Results for the design of experiment investigations of solketal production using the ST-DVB- $\mathrm{SO}_{3} \mathrm{H}$ copolymer beads for glycerol acetalization at 2:1-6:1 acetone to glycerol molar ratio, residence times of $1-20 \mathrm{~min}, 8.5 \mathrm{wt} \%$ of catalyst, and $30-50^{\circ} \mathrm{C}$ reaction temperatures, are shown in Table 2. The experimental data in Table 2 were analyzed by stepwise response surface methods using a Minitab 17 statistical software to obtain an empirical model for glycerol conversion to solketal ( $X$; shown in Equation 12), where MR is the acetone-to-glycerol molar ratio, $t$ is reaction time $(\mathrm{min})$, and $T$ is reaction temperature in ${ }^{\circ} \mathrm{C}$. Experimental error for the data in Table 1 was $\pm 2 \%$, and this was obtained from the three repeated experiments at run numbers 10 , 11 , and 15.

$$
\mathbf{X}(\%)=25.43+1.325 \mathrm{MR}+0.391 \mathrm{t}+0.637 \mathrm{~T}+0.1615 \mathrm{MR}^{*} \mathrm{t}
$$




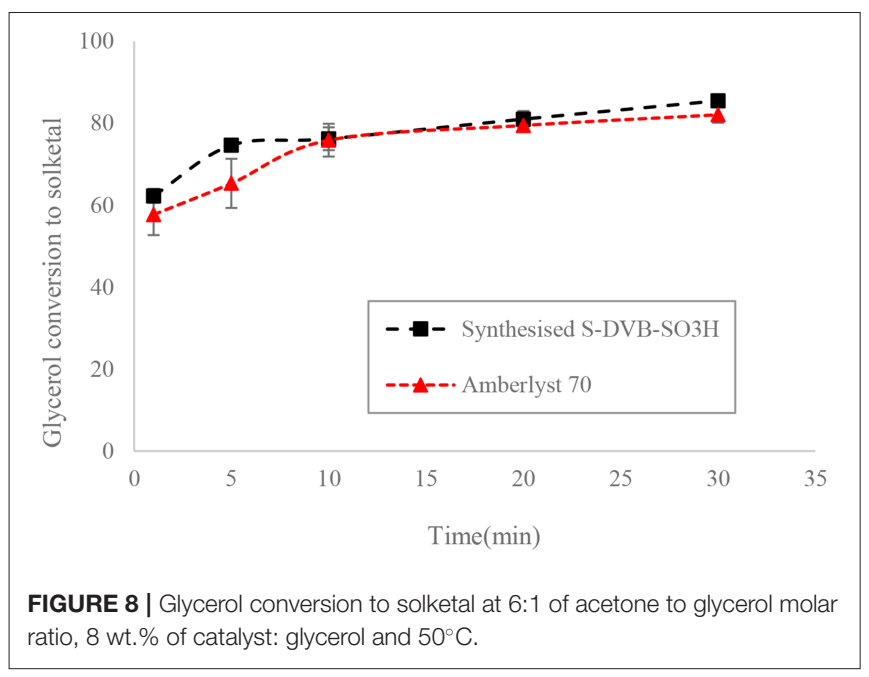

The empirical model in Equation 12 was used to generate the contour plots in Figure 9, showing the effects of the process variables. It is clear from Equation 12 that acetone to glycerol molar ratio has the strongest positive effect on the conversion of glycerol to solketal as the acetone to glycerol ratio can enhance the forward reaction (Nanda et al., 2014b) (see Figures 9A,B). A steady increase in the conversion of solketal can be observed from Figures 9B,C, when the reaction temperature increased. This is attributed to both the increasing inherent rate of reaction (Khayoon and Hameed, 2013) and decreased glycerol viscosity at high temperature. Similarly, high residence time was required to obtaine high glycerol to solketal conversion as shown in Figure 9C. The empirical equation for glycerol conversions to solketal was experimentally validated at the process conditions, and the results showed that the experimental conversions agreed well with predicted values.

Glycerol conversion to solketal is limited by thermodynamic equilibrium. This, for example, limits conversion to $81 \%$ at $4: 1$ of acetone to glycerol molar ratio and $50^{\circ} \mathrm{C}$ and to $87 \%$ at $6: 1$ and $40^{\circ} \mathrm{C}$ in the presence of 8.5 wt.\% of ST-DVB SO $\mathrm{SO}_{3} \mathrm{H}$ (as shown in Table 1). Other studies showed that solketal yield was $63.21 \%$ at $4: 1$ and $60^{\circ} \mathrm{C}$ with 1 wt. $\%$ of zeolite H-BEA (SAR 19) catalyst (Rossa et al., 2017) and $81 \%$ at $6: 1,70^{\circ} \mathrm{C}$, and 5 wt.\% of sulfonated carbon-silica catalyst after $30 \mathrm{~min}$ (Nandan et al., 2013). Clearly, the process conditions must be adjusted to overcome the equilibrium limitations. There is a need to increase solketal production from glycerol above the equilibrium conversions in the range of $75-80 \%$, commonly obtained in a single-stage process in the industry (Dmitriev et al., 2016).

Investigations of glycerol acetalization using the synthesized ST-DVB-SO3H catalyst indicate that high glycerol conversion to solketal could be obtained in a few minutes, with maximum conversion occurring in the range $2-20 \mathrm{~min}$ at $7: 1$ of acetone to glycerol molar ratio and $50^{\circ} \mathrm{C}$ as shown in Figure 10A, contrary to existing reports that equilibrium glycerol conversion to solketal requires residence times over $6 \mathrm{~h}$ at 1:2 of acetone to glycerol molar ratio and $80^{\circ} \mathrm{C}$ when mesoporous silicate HfTUD-1 catalyst was used ( $\mathrm{Li}$ et al., 2012) and $30 \mathrm{~min}$ at $6: 1$ of
TABLE 2 | Experimental data for glycerol conversions to solketal.

\begin{tabular}{lccccc}
\hline $\begin{array}{l}\text { Run } \\
\text { number }\end{array}$ & $\begin{array}{c}\text { Acetone/ } \\
\text { glycerol } \\
\text { molar } \\
\text { ratio }\end{array}$ & $\begin{array}{c}\text { Residence } \\
\text { time }(\mathbf{m i n})\end{array}$ & $\begin{array}{c}\text { Temperature } \\
\left({ }^{\circ} \mathbf{C}\right)\end{array}$ & $\begin{array}{c}\text { Glycerol conversion to } \\
\text { solketal (\%) }\end{array}$ \\
\cline { 5 - 6 } & & & & \multicolumn{3}{c}{$\begin{array}{c}\text { Experimental } \\
\text { values }\end{array}$} & $\begin{array}{c}\text { Predicted } \\
\text { values }\end{array}$ \\
\hline 1 & 4 & 20 & 50 & 81 & 83.3 \\
2 & 6 & 20 & 40 & 87 & 86 \\
3 & 4 & 1 & 50 & 62 & 63.6 \\
4 & 6 & 10.5 & 50 & 83 & 79.5 \\
5 & 2 & 20 & 40 & 70.9 & 67.8 \\
6 & 2 & 10.5 & 30 & 54.4 & 54.7 \\
7 & 6 & 10.5 & 30 & 66.7 & 66.7 \\
8 & 4 & 1 & 30 & 55 & 50.9 \\
9 & 6 & 1 & 40 & 56.4 & 60 \\
10 & 4 & 10.5 & 40 & 71.65 & 67 \\
11 & 4 & 10.5 & 40 & 69.96 & 67 \\
12 & 4 & 20 & 30 & 66.3 & 70.6 \\
13 & 2 & 1 & 40 & 52.5 & 54.3 \\
14 & 2 & 10.5 & 50 & 67.2 & 67.4 \\
15 & 4 & 10.5 & 40 & 67.8 & 67 \\
\hline & & & & &
\end{tabular}

acetone to glycerol molar ratio and $70^{\circ} \mathrm{C}$ when sulfonic acidmodified mesostructured silica (Ar-SBA-15) catalyst was used (Vicente et al., 2010). This indicated the catalytic activity of St-DVB catalyst for this reaction.

Previous studies have reported that $4: 1$ of acetone to glycerol molar ratio was an optimum condition to achieve $\approx 75 \%$ of glycerol conversion to solketal after $2 \mathrm{~h}$ using $\mathrm{SnCl}_{2}$ catalyst (Menezes et al., 2013) and $80 \%$ conversion after $1 \mathrm{~h}$ with amphiphilic catalysts (Souza et al., 2015). In this work, it was found that by increasing the acetone to glycerol molar ratio to $12: 1$, complete conversion (up to $98 \%$ of glycerol conversion) was obtained in only $30 \mathrm{~min}$ (as shown in Figure 10C). This is because, in addition to the high catalysis rate by the STDVB- $\mathrm{SO}_{3} \mathrm{H}$ catalyst, the use of acetone in excess shifts the thermodynamic equilibrium toward greater solketal formation, in accordance with Le Chatelier's principle.

Another effective route for achieving higher glycerol to solketal conversions was found to be through a two-stage acetalization process, which requires shorter reaction times under an economic reaction condition. The two-stage route applied a reaction at 10:1 acetone to glycerol molar ratio, with 8.5 wt.\% ST-DVB- $\mathrm{SO}_{3} \mathrm{H}$ copolymer catalyst, and $50^{\circ} \mathrm{C}$ for $10 \mathrm{~min}$ in the first step, followed by catalyst separation and drying in vacuum distillation at $40^{\circ} \mathrm{C}$ and $10 \mathrm{mbar}$ for $1 \mathrm{~h}$, and a second step reaction with the same amount of acetone of 10:1 molar ratio was added, $8.5 \mathrm{wt} . \%$ catalyst, and $50^{\circ} \mathrm{C}$ for another $10 \mathrm{~min}$. The two-stage process achieved about $99 \%$ glycerol to solketal conversion after a total reaction time of $20 \mathrm{~min}$ (as shown in Figure 10B). A multi-stage batch process has been used to slightly drive forward glycerol conversion to solketal at reaction temperature of $70^{\circ} \mathrm{C}$ and 5 wt.\% of propyl sulphonic acid-functionalized mesostructured silica catalyst, where $89.5 \%$ 

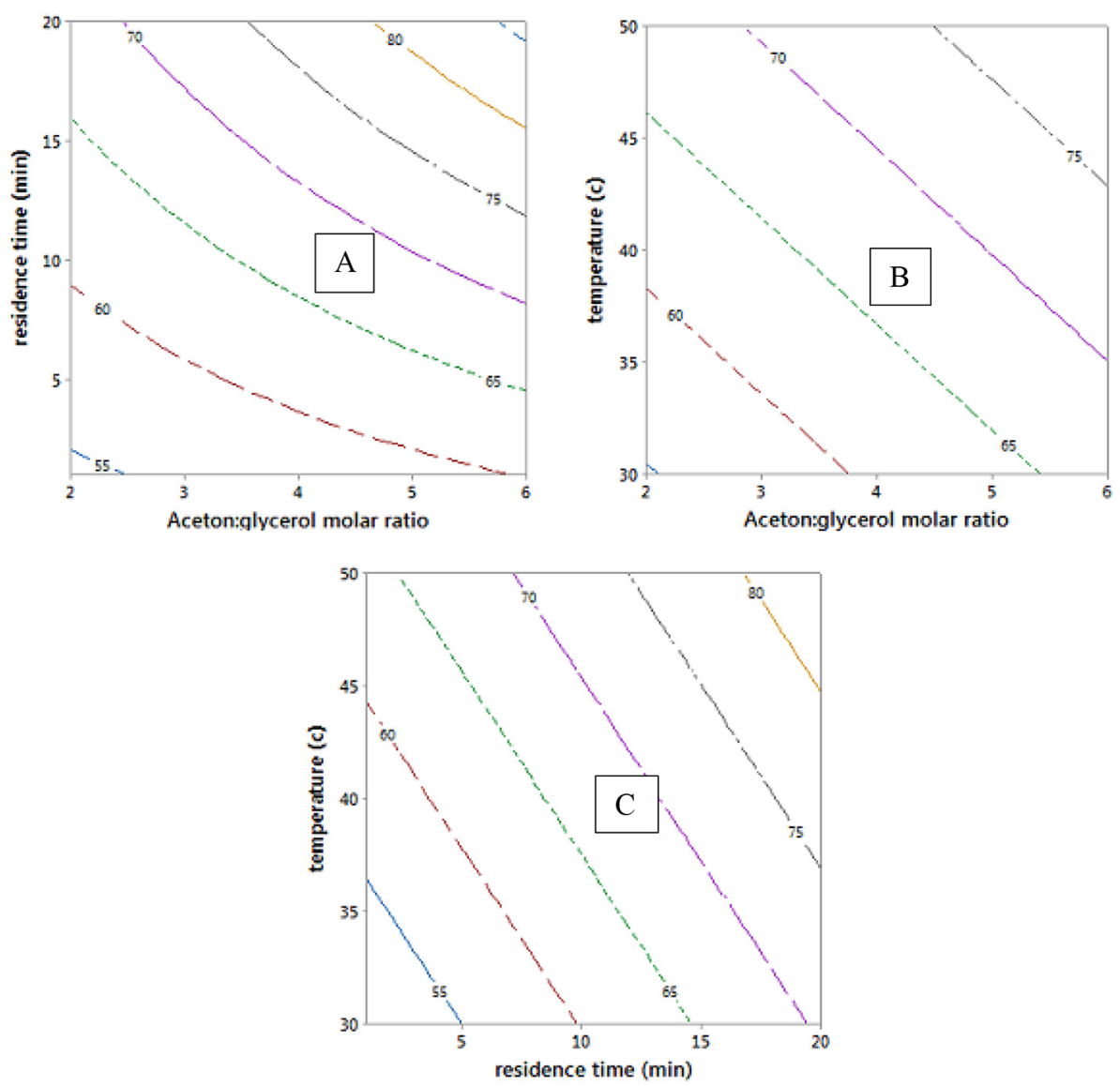

FIGURE 9 | Contour plots of glycerol conversion to solketal at hold values of $4: 1$ of acetone to oil molar ratio, 10.5 min of residence time, and $40^{\circ} \mathrm{C}$.

of glycerol conversion was obtained after the third step (Vicente et al., 2010). The lower solketal conversion in that study could be attributed to the higher temperature of $70^{\circ} \mathrm{C}$, which is well above the acetone boiling point, such that excessive loss of acetone during the reaction resulted in lower equilibrium solketal yield.

Figure 10D shows the results for the regeneration and reusability study for the ST-DVB- $\mathrm{SO}_{3} \mathrm{H}$ copolymer catalyst. The average glycerol conversion to solketal was about $81 \%$ for the fresh catalyst. Subsequent solketal conversions using the regenerated catalyst were $80 \%$ for the first recycle, $79 \%$ for the second recycle, and $81 \%$ for the third recycle. The results demonstrate that the catalyst can be regenerated by treatment with $0.1 \mathrm{M} \mathrm{HCl}$, followed by washing with de-ionized water and drying at $120^{\circ} \mathrm{C}$. CNS analysis performed on the fresh and spent ST-DVB- $\mathrm{SO}_{3} \mathrm{H}$ showed no change in composition for the fresh and spent catalysts, with the sulfur content remaining consistent between 8.6 and 8.63 wt.\% after three cycles.

These findings are consistent with an existing study, which reported that acid-functionalized ion-exchange resins are reusable (Pico et al., 2013; Eze et al., 2017). Therefore, the synthesized ST-DVB-SO $\mathrm{S}_{3} \mathrm{H}$ copolymer catalyst could be an ideal catalyst for continuous solketal production from glycerol byproduct in biodiesel processing.

\section{Techno-Economic Analysis of the Glycerol Acetalization Processes}

Techno-economic analysis was used to evaluate the viability of the three process conditions for solketal production as investigated in this study. These solketal process options were one-stage processes at low acetone molar ratio (6:1 of acetone to glycerol molar ratio) to achieve $87 \%$ solketal conversion, another one-stage process at higher acetone molar ratio (12:1) to achieve $98 \%$ solketal conversion, and a two-stage solketal process using 10:1 of acetone to glycerol molar ratio to obtain $98 \%$ solketal conversion. The techno-economic analysis of these three processes using the Aspen (HYSYS) showed that the total capital investment cost for the two-stage process was $\$ 27.5 \mathrm{M}, \$ 28.7 \mathrm{M}$ for the one-stage process at 12:1 acetone to glycerol molar ratio, and $\$ 29.42 \mathrm{M}$ for the one-stage process at 6:1 acetone to glycerol molar ratio (as shown in Table 3).

As shown in Table 3, the net revenue from the two-stage process was $\$ 119.36 \mathrm{M}$, which was slightly higher than $\$ 118.85 \mathrm{M}$ for the one-stage process at 12:1 acetone to glycerol molar ratio, and $\$ 67.2 \mathrm{M}$ for the one-stage process at $6: 1$ acetone to glycerol molar ratio. The NPV for the three glycerol acetalization process options follows similar trends as the net revenue. The NPV of the two-stage process was $\$ 707 \mathrm{M}$, which was higher than $\$ 703 \mathrm{M}$ for 


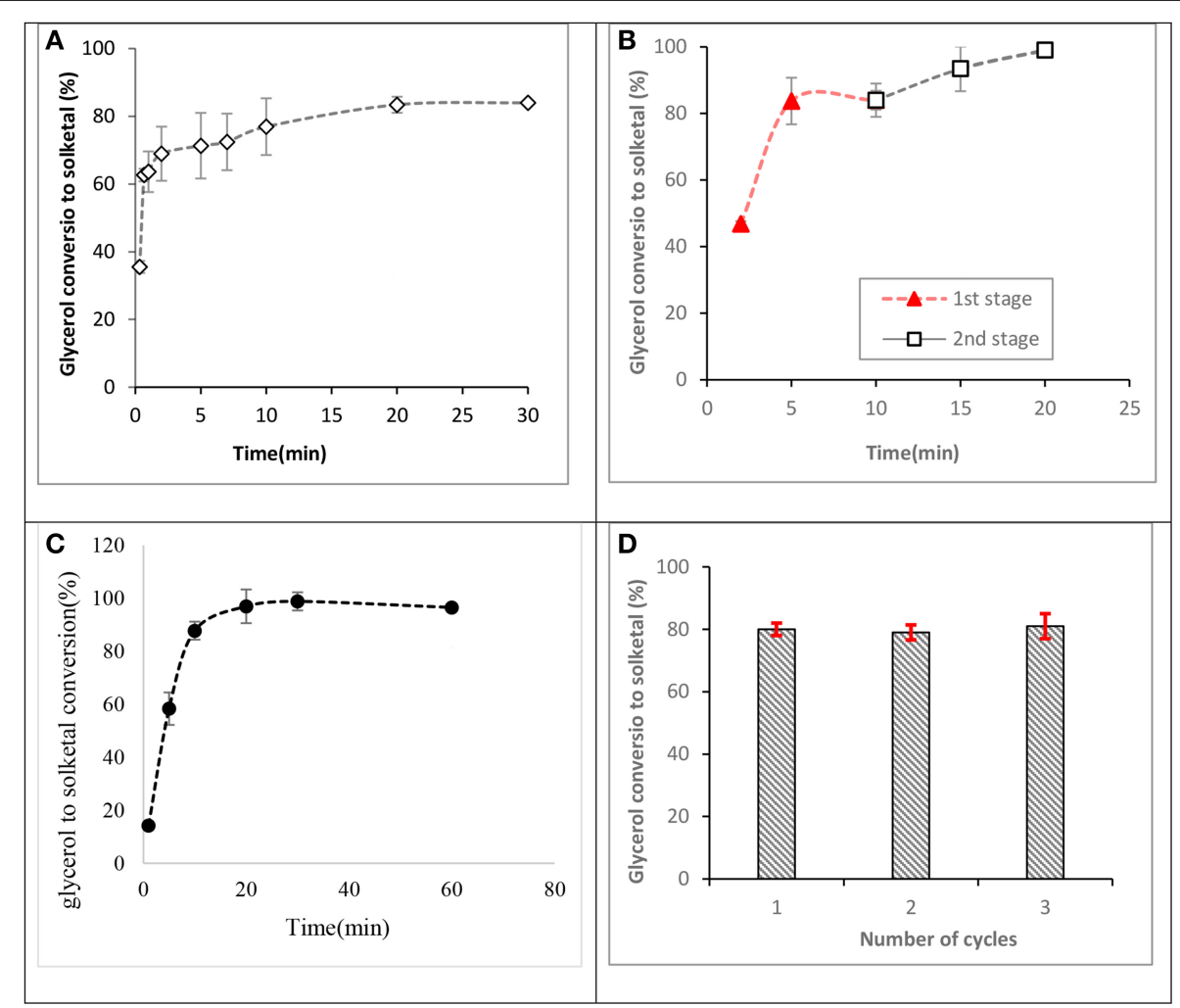

FIGURE 10 | Glycerol conversions to solketal at $50^{\circ} \mathrm{C}$. (A) Reaction profile for a fresh catalyst at 7:1 of acetone to glycerol molar ratio and 8.5 wt.\% of catalyst to glycerol, (B) a two-stage process at 10:1 of acetone to glycerol molar ratio and 8.5 wt.\% of ST-DVB-SO3H catalyst to glycerol, (C) $12: 1$ of acetone to glycerol molar ratio and 8.5 wt. \% of ST-DVB-SO3H catalyst, and (D) reusability of the styrene-DVB copolymer catalyst at 12:1 of acetone to glycerol molar ratio, and 5 wt.\% of $\mathrm{ST}-\mathrm{DVB}-\mathrm{SO}_{3} \mathrm{H}$ catalyst to glycerol at $2 \mathrm{~h}$.

TABLE 3 | Economic evaluation of three different plants to produce solketal from glycerol acetalization (100,000 tons/year).

\begin{tabular}{llll}
\hline $\begin{array}{l}\text { Techno- } \\
\text { economic } \\
\text { parameters }\end{array}$ & $\begin{array}{l}\text { One-stage } \\
\text { process } \\
(\mathbf{1 2 : 1} \text { molar } \\
\text { ratio) }\end{array}$ & $\begin{array}{l}\text { One-stage } \\
\text { process (6:1 } \\
\text { molar ratio) }\end{array}$ & $\begin{array}{l}\text { Two-stage } \\
\text { process } \\
\text { (10:1 molar } \\
\text { ratio) }\end{array}$ \\
\hline TCl $(\$ / M)$ & 28.7 & 29.42 & 27.5 \\
$\begin{array}{l}\text { Operating } \\
\text { cost }(\$ / M)\end{array}$ & 17.2 & 13.8 & 15.7 \\
$\begin{array}{l}\text { Utility cost } \\
(\$ / M)\end{array}$ & 14.7 & 11.4 & 13.26 \\
$\begin{array}{l}\text { Annual net } \\
\text { revenue }(\$ / M)\end{array}$ & 118.85 & 67.2 & 119.36 \\
$\begin{array}{l}\text { NPV }(\$ / M) \text { at } \\
20 \text { years }\end{array}$ & 703 & 384 & 707 \\
$\begin{array}{l}\text { Break-even } \\
\text { price }(\$ / \text { ton })\end{array}$ & 2,058 & 2,088 & 2,058 \\
\hline
\end{tabular}

the one-stage process at 12:1 acetone to glycerol molar ratio, and $\$ 384 \mathrm{M}$ for the one-stage process at 6:1 acetone to glycerol molar ratio. This was attributed to the higher cost of the distillation columns that were used in the purification steps of solketal in one-stage process (6:1 of acetone to glycerol molar ratio) to separate solketal from the high amount of glycerol and water. Only one distillation column was used in the purification step of solketal in the one-stage process (12:1 of acetone to glycerol) to separate ( $98 \%$ solketal and $2 \%$ of glycerol) from water. No purification step was required in the two-stage process as the formed product was separated from the first step and only a small amount of water $(0.16 \% \approx 0)$ was formed in the last stage.

Consequently, the break-even prices of solketal for these processes were reduced to $\$ 2,058 /$ ton for the one-stage at 12:1 acetone molar ratio and two-stage process and to $\$ 2,088 /$ ton for the one-stage at 6:1 acetone molar ratio, which are all lower than the current price of \$3,000/ton for solketal (Alibaba, 2018).

The sensitivity analysis of acetone, glycerol, and solketal were evaluated by varying their prices from -50 to $50 \%$ for 20 years at $15.3 \%$ discount rate (Figure 11). As shown in Figures 11A-C, increase in glycerol prices by $10 \%$ resulted in decrease in the $\mathrm{NPV}$ by about $\$ 52.53 \mathrm{M}$ for the one-stage process at 12:1 acetone, $\$ 59.18 \mathrm{M}$ for the one-stage process at 6:1 acetone, and $\$ 52.53 \mathrm{M}$ for the two-stage process at 10:1 acetone. Increasing the acetone price also had a huge effect on the plant's NPV. For instance, a $10 \%$ increase in the acetone price resulted in reductions of the NPV by $\$ 27.6 \mathrm{M}, \$ 31.1 \mathrm{M}$, and \$27.6 M for the one-stage process at 12:1 acetone, one-stage process at 6:1 acetone, and two-stage process at 10:1 acetone, respectively. On the contrary, increasing 


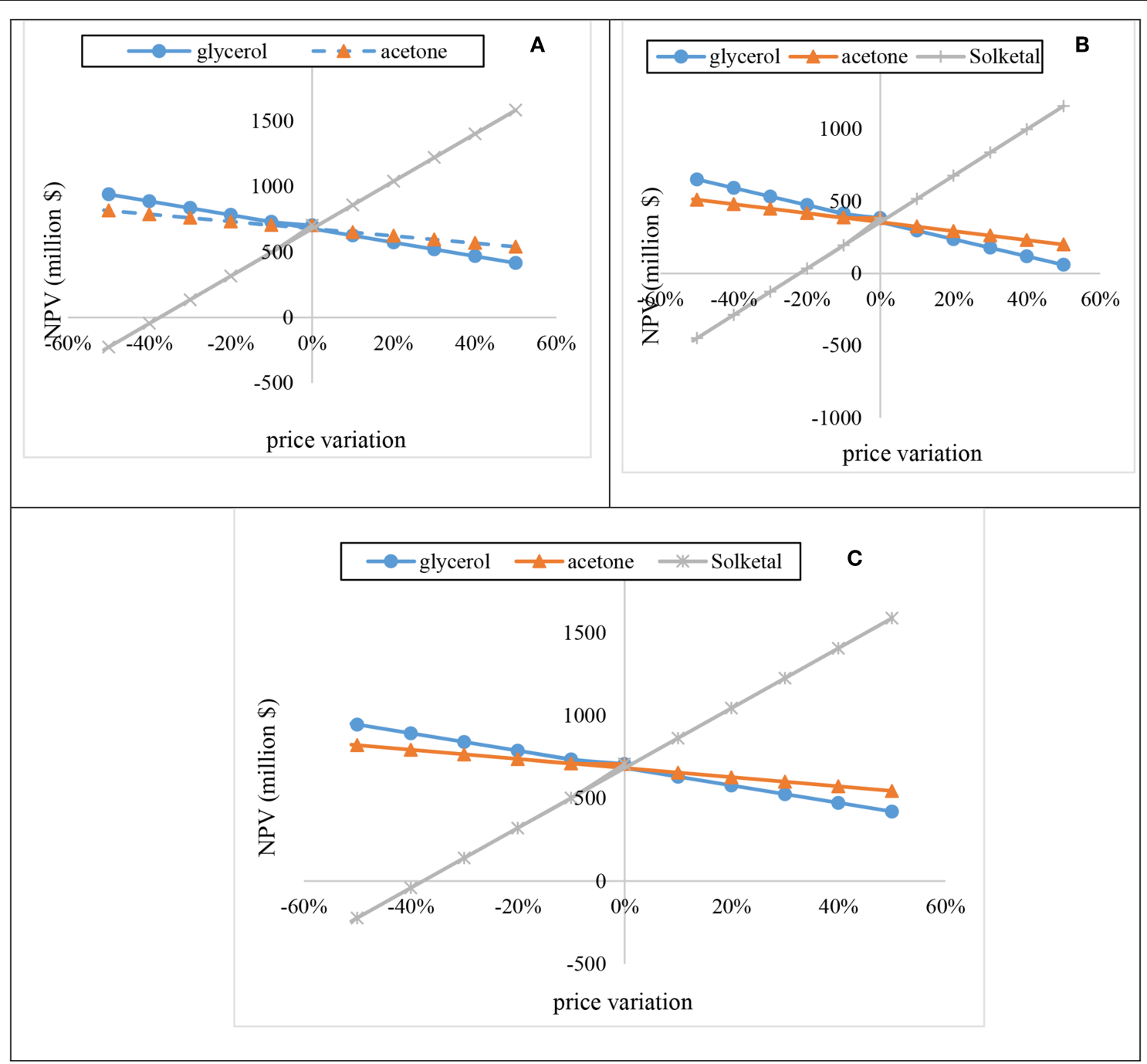

FIGURE 11 | Sensitivity of the process NPV to fluctuations in reactants (acetone and glycerol) and product (solketal) prices.

the solketal price by $10 \%$ resulted in a substantial rise in the NPV. As shown in Figures 11A-C, a 10\% rise in the solketal price resulted in NPV rise by $\sim \$ 181 \mathrm{M}$ for one-stage (12:1) and two-stage plants.

\section{CONCLUSION}

Styrene-divinylbenzene copolymer beads of desired physical properties were synthesized and functionalized for catalytic application in glycerol conversion to solketal. Mixing intensity had a profound effect on the particle size of the copolymer beads, while the DVB and diluent contents determined the degrees of crosslinking and porosity of the beads, respectively. The copolymer beads with the most desirable physical properties (high mechanical stability, porosity, and surface area) were derivatized with sulphonic acid and used in the catalysis of glycerol acetalization with acetone under mild reaction conditions $\left(30-50^{\circ} \mathrm{C}, 2-30 \mathrm{~min}\right.$ reaction time,
8.5 wt.\% of the catalyst, and 2:1-12:1 acetone to glycerol molar ratio. Both the synthesis of the copolymer beads and the glycerol acetalization processes were investigated using design of experiments (response surface methodology), leading to empirical models for optimization of particle sizes, beads surface area, and swelling ratio. The sulphonic acid-functionalized styrene-divinylbenzene copolymer beads synthesized in this work were found to be catalytically active. This catalyst has similar catalytic activity as the AmberlystTM 70 obtained from Dow Chemical Company, Netherlands. Generally, the glycerol conversion to solketal increased with reaction temperature, residence time, and acetone to glycerol molar ratio.

Three process conditions for glycerol valorization to solketal using a synthesized sulphonic acid-functionalized styrene-divinylbenzene (ST-DVB- $\mathrm{SO}_{3} \mathrm{H}$ ) copolymer catalyst were investigated. The ST-DVB- $\mathrm{SO}_{3} \mathrm{H}$ copolymer beads were obtained by copolymerization of 36 wt.\% styrene and 64 wt.\% 
divinylbenzene monomer mixture in $84 \mathrm{wt}$.\% diluent based on the total monomer solution, followed by sulphonic acid site functionalization. The ST-DVB- $\mathrm{SO}_{3} \mathrm{H}$ beads produced were spherical of $340 \mu \mathrm{m}$ mean particles diameter and $2.64 \mathrm{mmol}$ of $\mathrm{SO}_{3} \mathrm{H}$ active sites per gram were produced. Under three processes at $50^{\circ} \mathrm{C}$ and 8.5 wt.\% of ST-DVB: single-stage process (1) 6:1 of acetone to glycerol molar ratio, (2) 12:1 of acetone to glycerol molar ratio to achieve $87 \%$ and $\geq 98 \%$ of solketal yield from each process, respectively, and two stages process at 10:1 of acetone to glycerol molar ratio to obtain $\geq 98 \%$.

Techno-economic analysis was performed using Aspen (HYSYS) for a fixed capacity of 100,000 ton/years and 20years lifetime, based on the 30 -min reaction time. The technoeconomic analysis of the three solketal process options at fixed capacity of 100,000 ton/years and 20-years lifetime showed that

\section{REFERENCES}

Alibaba (2018). Chemicals Categories. Available online at: www.alibaba.com

Ashby, R., Solaiman, D. Y., and Foglia, T. (2004). Bacterial poly(hydroxyalkanoate) polymer production from the biodiesel co-product stream. J. Polym. Environ. 12, 105-112. doi: 10.1023/B:JOOE.0000038541.54263.d9

Boz, N., Nebahat, D., and Kalyon, D. M. (2015). Esterification and transesterification of waste cooking oil over Amberlyst 15 and modified Amberlyst 15 catalysts. Appl. Catal. B Environ. 165, 723-730. doi: 10.1016/j.apcatb.2014.10.079

Ciriminna, R., Della Pina, C., Rossi, M., and Pagliaro, M. (2014). Understanding the glycerol market. Eur. J. Lipid Sci. Technol. 116, 1432-1439. doi: 10.1002/ejlt.201400229

Coutinho, F. M. B., Teixeira, V. G., and Barbosa, C. R. (1998). Synthesis and characterization of styrene-divinylbenzene loaded with $\operatorname{di}(2$ ethylhexyl)phosphonic acid. I. Influence of diluent mixture on the porous structure of the copolymer. J. Appl. Polymer Sci. 67, 781-787. doi: 10.1002/ (SICI)1097-4628(19980131)67:5<781::AID-APP2>3.0.CO;2-P

da Silva, M. J., Ávila Rodrigues, F., and Júlio, A. A. (2017). SnF2-catalyzed glycerol ketalization: a friendly environmentally process to synthesize solketal at room temperature over on solid and reusable Lewis acid. Chem. Eng. J. 307, 828-835. doi: 10.1016/j.cej.2016.09.002

Demirbas, A. (2008). A Realistic Fuel Alternative for Diesel Engines. 1st Edn. London: Springer. p. 1-208.

Dmitriev, G. S., Terekhov, A. V., Zanaveskin, L. N., Khadzhiev, S. N., Zanaveskin, K. L., Maksimov, A. L. (2016). Choice of a catalyst and technological scheme for synthesis of solketal. Russian J. Appl. Chem. 89, 1619-1624. doi: 10.1134/S1070427216100094

Durie, S., Jerabek, K., Mason, C., and Sherrington, D. C. (2002). One-pot synthesis of branched poly(styrene-divinylbenzene) suspension polymerized resins. Macromolecules 35, 9665-9672. doi: 10.1021/ma0209794

Eze, V. C., and Harvey, A. P. (2018). Continuous reactive coupling of glycerol and acetone-a strategy for triglyceride transesterification and in-situ valorisation of glycerol by-product. Chem. Eng. J. 347, 41-51. doi: 10.1016/j.cej.2018.04.078

Eze, V. C., Phan, A., and Harvey, P. A. (2017). Intensification of carboxylic acid esterification using a solid catalyst in a mesoscale oscillatory baffled reactor platform. Chem. Eng. J. 322, 205-214. doi: 10.1016/j.cej.2017.04.038

Fu, J., and Borges, M. E. (2015). Free fatty acids esterification for biodiesel production using self-synthesized macroporous cation exchange resin as solid acid catalyst. Fuel 154, 1-8. doi: 10.1016/j.fuel.2015.03.048

Gokmen, M. T., and Du Prez, F. E. (2012). Porous polymer particles-a comprehensive guide to synthesis, characterization, functionalization and applications. Progr. Polymer Sci. 37, 365-405. doi: 10.1016/j.progpolymsci.2011.07.006

Helwani, Z., Othman, M. R., Aziz, N., Fernando, W. J. N., and Kim, J. (2009). Technologies for production of biodiesel focusing on green the net present values for the solketal process options were $\$ 707 \mathrm{M}$ for the two-stage, $\$ 703 \mathrm{M}$ for the one-stage at 6:1 acetone to glycerol molar ratio, and $\$ 384 \mathrm{M}$ for one-stage at 12:1 acetone to glycerol molar ratio.

\section{AUTHOR CONTRIBUTIONS}

LA-S collected all the data and wrote the first draft of the paper. This work was done under VE and AH supervision.

\section{ACKNOWLEDGMENTS}

The authors would like to thank the Higher Committee for Education Development in Iraq (HCED) for their financial support. catalytic techniques: a review. Fuel Proc. Technol. 90, 1502-1514. doi: 10.1016/j.fuproc.2009.07.016

Huang, D., Wang, Z., and Yuan, Z. (2012). Pretreatment of trap grease with Amberlyst-15 for biodiesel production. Adv. Mater. Res. 347-353, 2528-2531. doi: 10.4028/www.scientific.net/AMR.347-353.2528

Kangwansupamonkon, W., Damronglerd, S., and Kiatkamjornwong, S. (2002). Effects of the crosslinking agent and diluents on bead properties of styrene-divinylbenzene copolymers. J. Appl. Polymer Sci. 85, 654-669. doi: 10.1002/app.10620

Khayoon, M. S., and Hameed, B. H. (2013). Solventless acetalization of glycerol with acetone to fuel oxygenates over $\mathrm{Ni}-\mathrm{Zr}$ supported on mesoporous activated carbon catalyst. Appl. Catal. A Gen. 464-465(Suppl. C), 191-199. doi: 10.1016/j.apcata.2013.05.035

Kim, M. J., Kim, M. Y., Kwon, O. Z., and Seo, G. (2011). Transesterification of vegetable oils over a phosphazenium hydroxide catalyst incorporated onto silica. Fuel Proc. Technol. 92, 126-131. doi: 10.1016/j.fuproc.2010. 09.015

Knothe, G., Krahl, J., and Van Gerpen, J. (2010). The Biodiesel Handbook, 2nd Edn. Biodiesel Handbook. p. 1-501.

Leoneti, A. B., Aragão-Leoneti, V., and Oliveira, S. V. W. B. (2012). Glycerol as a by-product of biodiesel production in Brazil: alternatives for the use of unrefined glycerol. Renew. Energy 45, 138-145. doi: 10.1016/j.renene.2012.02.032

Leung, D. Y. C., Wu, X., and Leung, K. H. (2010). A review on biodiesel production using catalyzed transesterification. Appl. Energy 87, 1083-1095. doi: 10.1016/j.apenergy.2009.10.006

Li, L., Korányi, T. I., and Hensen, E. J. M. (2012). Highly-efficient conversion of glycerol to solketal over heterogeneous Lewis acid catalysts. Green Chem. 14, 1611-1619. doi: 10.1039/c2gc16619d

Melero, J. A., Iglesias, J., and Morales, G. (2009). Heterogeneous acid catalysts for biodiesel production: current status and future challenges. Green Chem. 11, 1285-1308. doi: 10.1039/b902086a

Menezes, F. D. L., Guimaraes, M. D. O., and da Silva, M. J. (2013). Highly selective $\mathrm{SnCl} 2$-catalyzed solketal synthesis at room temperature. Industr. Eng. Chem. Res. 52, 16709-16713. doi: 10.1021/ie402240j

Mota, C. J. A., da Silva, C. X., Rosenbatch, N., Costa, J., and da Silva, F. (2010). Glycerin derivatives as fuel additives: the addition of glycerol/acetone ketal (solketal) in gasolines. Energy Fuels 24, 2733-2736. doi: 10.1021/ef9015735

Mu, Y., Teng, H., Zhang, D. J., Wang, W., and Xiu, Z.-L. (2006). Microbial production of 1,3-propanediol by Klebsiella pneumoniae using crude glycerol from biodiesel preparations. Biotechnol. Lett. 28, 1755-1759. doi: 10.1007/s10529-006-9154-Z

Nanda, M. R., Yuan, Z., Qin, W., Ghaziaskar, H. S., Poirier, M. A., and Xu, C. (2014a). Catalytic conversion of glycerol to oxygenated fuel additive in a continuous flow reactor: process optimization. Fuel 128, 113-119. doi: 10.1016/j.fuel.2014.02.068 
Nanda, M. R., Yuan, Z., Qin, W., Ghaziaskar, H. S., Poirier, M. A., and Xu, C. (2014b). Thermodynamic and kinetic studies of a catalytic process to convert glycerol into solketal as an oxygenated fuel additive. Fuel 117 (Part A), 470-477. doi: 10.1016/j.fuel.2013.09.066

Nandan, D., Peta, S., Konathala, L. N. S., Kumar, M., and Nagabhatla, V. (2013). Acid functionalized carbon-silica composite and its application for solketal production. Microp. Mesop. Mater. 179, 182-190. doi: 10.1016/j.micromeso.2013.06.004

Özbay, N., Oktar, N., and Tapan, N. A. (2008). Esterification of free fatty acids in waste cooking oils (WCO): role of ion-exchange resins. Fuel 87, 1789-1798. doi: 10.1016/j.fuel.2007.12.010

Papanikolaou, S., Muniglia, L., Chevalot, I., Aggelis, G., and Marc, I. (2002). Yarrowia lipolytica as a potential producer of citric acid from raw glycerol. J. Appl. Microbiol. 92, 737-744. doi: 10.1046/j.1365-2672.2002.01577.x

Park, S.-H., Park, J.-H., Gobikrishnan, S., Jeong, G.-T., and Park, D.-H. (2015). Biodiesel production from palm oil using a non-catalyzed supercritical process. Korean J. Chem. Eng. 32, 2290-2294. doi: 10.1007/s11814-015-0203-y

Patil, P. D., Gude, V. G., and Deng, S. (2009). Biodiesel production from Jatropha curcas, waste cooking, and Camelina sativa oils. Ind. Eng. Chem. Res. 48, 10850-10856. doi: 10.1021/ie901146c

Pico, M. P., Rosas, J. M., Rodriguos, S., Santos, A., and Romero, A. (2013). Glycerol etherification over acid ion exchange resins: effect of catalyst concentration and reusability. J. Chem. Technol. Biotechnol. 88, 2027-2038. doi: 10.1002/jctb.4063

Rodrigues, R., Isoda, N., Goncalves, M., Figueiredo, F. C. A., Mandelli, D., and Carvalho, W. A. (2012). Effect of niobia and alumina as support for Pt catalysts in the hydrogenolysis of glycerol. Chem. Eng. J. 198-199, 457-467. doi: 10.1016/j.cej.2012.06.002

Rossa, V., Pessanha, Y. S. P., Diaz, G., Diogenes, L., Camara, T., Pergher, S. B. C., et al. (2017). Reaction kinetic study of solketal production from glycerol ketalization with acetone. Industr. Eng. Chem. Res. 56, 479-488. doi: 10.1021/acs.iecr.6b03581

Sakdasri, W., Sawangkeaw, R., and Ngamprasertsith, S. (2018). Techno-economic analysis of biodiesel production from palm oil with supercritical methanol at a low molar ratio. Energy 152, 144-153. doi: 10.1016/j.energy.2018.03.125
Sharma, Y. C., Singh, B., and Korstad, J. (2011). Advancements in solid acid catalysts for ecofriendly and economically viable synthesis of biodiesel. Biofuels Bioprod. Bioref. 5, 69-92. doi: 10.1002/bbb.253

Souza, T. E., Padula, I. D., Teodoro, M. M. G., Chagas, P., Resende, J. M., Souzza, P. P., et al. (2015). Amphiphilic property of niobium oxyhydroxide for waste glycerol conversion to produce solketal. Catalysis Today 254, 83-89. doi: $10.1016 /$ j.cattod.2014.12.027

Suriyaprapadilok, N., and Kitiyanan, B. (2011). Synthesis of solketal from glycerol and its reaction with benzyl alcohol. Energy Proc. 9, 63-69. doi: 10.1016/j.egypro.2011.09.008

Tesser, R., Di Serio, M., Casale, L., Sannino, L., Ledda, M., and Santacesaria, E. (2010). Acid exchange resins deactivation in the esterification of free fatty acids. Chem. Eng. J. 161, 212-222. doi: 10.1016/j.cej.2010. 04.026

Vicente, G., Melero, J. A., Morales, G., Paniagua, M., and Martin, E. (2010). Acetalisation of bio-glycerol with acetone to produce solketal over sulfonic mesostructured silicas. Green Chem. 12, 899-907. doi: 10.1039/b923681c

Yang, F., Hanna, M. A., and Sun, R. (2012). Value-added uses for crude glycerol a byproduct of biodiesel production. Biotechnol. Biofuels 5:13. doi: 10.1186/1754-6834-5-13

Yussof, W. M. H. W. (2012). Evaluation of Heterogeneous Quaternary Ammonium Catalysts for Transesterification of Triglycerides. Newcastle University.

Conflict of Interest: The authors declare that the research was conducted in the absence of any commercial or financial relationships that could be construed as a potential conflict of interest.

Copyright (c) 2020 Al-Saadi, Eze and Harvey. This is an open-access article distributed under the terms of the Creative Commons Attribution License (CC BY).

The use, distribution or reproduction in other forums is permitted, provided the original author(s) and the copyright owner(s) are credited and that the original publication in this journal is cited, in accordance with accepted academic practice. No use, distribution or reproduction is permitted which does not comply with these terms. 